\title{
Efeitos genéticos aditivos e não-aditivos em características de crescimento, reprodutivas e habilidade materna em ovinos das raças Santa Inês, Somalis Brasileira, Dorper e Poll Dorset ${ }^{1}$
}

\section{Adriano Caminha Barbosa Neto², Sônia Maria Pinheiro de Oliveira ${ }^{3}$, Olivardo Facó 4 , Raimundo Nonato Braga Lôbo ${ }^{3,4}$}

\author{
${ }^{1}$ Projeto financiado pela FUNCAP - Fundação Cearense de Apoio ao Desenvolvimento Científico e Tecnológico, por intermédio da bolsa de \\ Mestrado. \\ 2 Pós-Graduação em Zootecnia da UFC. Bolsista FUNCAP. \\ 3 Pós-Graduação em Zootecnia da UFC. \\ ${ }^{4}$ Embrapa Caprinos.
}

RESUMO - Efeitos genético aditivo, de dominância e de recombinação em cruzamentos entre as raças Santa Inês (SI), Somalis Brasileira (So), Dorper (Do) e Poll Dorset (Po) foram estimados para as características de crescimento, reprodutivas e de habilidade materna. Os dados foram obtidos da Gaasa e Alimentos LTDA, uma empresa que participa do Programa de Melhoramento Genético de Caprinos e Ovinos (GENECOC) da Embrapa Caprinos. Inicialmente, 3.573 registros foram analisados por meio do procedimento MIXED do pacote estatístico SAS (1999). As análises foram realizadas considerando os efeitos da diferença genética aditiva entre as raças, de dominância e de recombinação. O peso ao nascer foi influenciado pelos efeitos genéticos aditivos, enquanto o peso ao desmame e o ganho de peso pré-desmame foram influenciados por efeitos genéticos não-aditivos. A estimativa de herdabilidade direta para o peso ao nascer foi moderada, o que indica a existência de variabilidade genética passível de ser explorada por meio da seleção individual. Do mesmo modo, as estimativas de herdabilidade das características idade ao primeiro parto e peso total das crias ao nascer indicaram a existência de variabilidade genética para obter ganhos genéticos por meio da seleção. Os genes das raças Poll Dorset e Dorper tiveram papel importante para melhor desempenho ponderal, portanto, essas raças podem ser indicadas como paternas no cruzamento terminal. A utilização de matrizes F1 Santa Inês $\times$ Somalis Brasileira em cruzamentos com reprodutores Poll Dorset pode levar a maior eficiência reprodutiva.

Palavras-chave: cruzamentos, desempenho produtivo, efeitos epistáticos, heterose

\section{Additive and non-additive genetic effects on growth, reproductive and maternal traits in sheep of Santa Inês, Brazilian Somali, Dorper and Poll Dorset breeds}

\begin{abstract}
Additive genetic, dominance and recombination effects in breedings among Santa Inês (SI), Brazilian Somali (So), Dorper (Do) and Poll Dorset (Po) breeds were estimated for growth, reproductive and maternal hability traits. Data were obtained from Gaasa e Alimentos LTDA, a company that participates on the Programa de Melhoramento Genético de Caprinos e Ovinos (GENECOC) coordinated by Embrapa Caprinos. Initially, 3,573 records were analyzed using the MIXED procedure of the statistical package SAS (1999). The analyses were carried out considering the effects of additive genetic difference among breeds, dominance and recombination effects. Birth weight was mainly influenced by additive genetic effects, while weaning weight and pre-weaning weight gain were influenced by non-additive genetic effects. Direct heritability estimates for birth weight was moderate indicating that there is genetic variability believable to be exploited by individual selection. In the same way, heritability estimates for the traits age at first lambing and litter total weight at birth indicated the existence of genetic variability to obtain genetic gains through selection. Genes of the Poll Dorset and Dorper breeds had an important role for a better growth performance, therefore, these breeds can be indicated as sires in the terminal breeds. The use of F1 Santa Inês $\times$ Brazilian Somali females on crossbreeding with Poll Dorset rams can lead to a better reproductive efficiency.
\end{abstract}

Key Words: crossbreeding, epistatic effects, heterosis, productive performance 


\section{Introdução}

A ovinocultura tem apresentado mudanças, deixando de ser uma atividade de subsistência e tornando-se uma exploração empresarial e especializada (Costa, 2007). Essa mudança pode ser observada com a expansão da raça Santa Inês e com a introdução de algumas raças exóticas, como a Dorper, que é reconhecidamente explorada para produção de carne (Sousa, W. et al., 2006). Uma das alternativas para incrementar a produção brasileira por meio do melhoramento genético animal seria o aproveitamento do potencial das diferentes raças e/ou grupos genéticos, utilizando estratégias de cruzamentos, acompanhadas da seleção.

Os fatores primordiais que motivam o uso do cruzamento são aproveitar as vantagens da heterose, utilizar a “complementaridade”, ou seja, combinar características desejáveis de duas ou mais raças ou linhagens, possibilitar a incorporação de material genético desejável de forma rápida e, também, a formação de raças sintéticas (Euclides Filho, 1996). A heterose é a diferença entre a média da característica avaliada nos mestiços e a média dessa mesma característica medida nos pais (Ferraz \& Eler, 2005). O aumento do vigor nos descendentes de cruzamentos é denominado vigor híbrido, o qual é causado pelo aumento da heterozigose.

Os cruzamentos visam explorar características econômicas, particularmente aquelas em que a seleção individual é pouco efetiva, bem como a restauração do poder adaptativo perdido com a endogamia (Falconer \& Mackey, 1996). A escolha do tipo de cruzamento depende de inúmeros fatores, dentre os quais: número de matrizes aptas a serem cruzadas, disponibilidade de alimento para os animais, mão de obra disponível e qualificada e possibilidade de retorno dos investimentos (Pereira, 2004).

No Brasil são poucos os registros da estimativa de efeitos genéticos nos cruzamentos em ovinos. Assim, o objetivo deste trabalho foi avaliar os efeitos da diferença genética aditiva, da dominância e da recombinação para os pesos corporais ao nascimento e à desmama, o ganho de peso diário entre as pesagens, os pesos totais das crias ao nascer e ao desmame, a idade ao primeiro parto, o intervalo de partos e o período de gestação entre os vários grupos genéticos oriundos dos cruzamentos entre as raças Santa Inês, Somalis Brasileira, Dorper e Poll Dorset.

\section{Material e Métodos}

Os dados utilizados neste estudo foram de animais puros e mestiços das raças Santa Inês, Somalis Brasileira,
Dorper e Poll Dorset da fazenda Gaasa e Alimentos Ltda., localizada no Município de Inhumas-GO, assistida pelo Programa de Melhoramento Genético de Caprinos e Ovinos de Corte (GENECOC) da Embrapa Caprinos. Os animais foram criados em regime semi-intensivo, entre os anos de 1998 e 2007, alimentados com pastagem de tifton 85 , silagem e suplementados com ração concentrada com $21 \%$ de proteína bruta para as crias e borregas e $15 \%$ de proteína bruta para as demais categorias.

Foram analisadas as características peso ao nascer (PN), peso ao desmame (PD) e ganho de peso do nascimento ao desmame (GP), peso total das crias ao nascer (PTCN), peso total das crias ao desmame (PTCD), idade ao primeiro parto (IPP), intervalo de partos (IDP) e período de gestação (PG). Na definição sobre quais variáveis deveriam ser consideradas nos modelos estatísticos para as estimativas dos efeitos genéticos aditivos e não-aditivos, utilizou-se o procedimento MIXED do pacote estatístico SAS (1999). Entre as variáveis testadas foram grupos contemporâneos (GC), os quais foram compostos por animais nascidos no mesmo mês e ano de nascimento e pertencentes ao mesmo sexo, classes para idade da mãe ao parto, ordem de parto (OP), sexo (SX) e tipo de parto (TP) para todos os grupos contemporâneos. Foram considerados nas análises apenas os registros de animais com pai e mãe conhecidos, dada a impossibilidade de se calcular corretamente as covariáveis para a obtenção das estimativas dos efeitos genéticos aditivos, de heterose individual e materna e o efeito de recombinação, sem o conhecimento do grupo genético dos pais. Foram excluídas das análises as informações consideradas atípicas, tais como idade ao primeiro parto acima de 1340 dias e intervalo de partos acima de 800 dias. Para as análises das características de habilidade materna e reprodutivas foram desconsiderados os dados de matrizes que tinham genes da raça Dorper em função do pequeno número de observações. Após serem feitas essas restrições, restaram, 3573, 2797, 2797, 2967, 2824, 986, 1952 e 2716 registros de peso ao nascer, peso ao desmame, ganho de peso, peso total das crias ao nascer, peso total das crias ao desmame, idade ao primeiro parto, intervalo de partos e período de gestação, respectivamente.

De acordo com Van der Werf \& De Boer (1989), Akbas et al. (1993) e Bocchi et al. (2008), o uso dos modelos mistos permite a estimativa de parâmetros genéticos e dos efeitos dos cruzamentos simultaneamente. Assim, para cada uma das características estudadas, estimativas dos componentes de covariância, de parâmetros genéticos e de efeitos genéticos aditivos e não-aditivos dos cruzamentos foram obtidas pelo método da máxima verossimilhança 
restrita (REML), sob modelo animal, utilizando o sistema computacional MTDFREML (Boldman et al., 1995) e adotando $10^{-9}$ como critério de convergência.

Como todas as análises, para todas as características, foram realizadas com modelo animal unicaracterística, as correlações genéticas entre as características estudadas foram estimadas a partir da correlação de Pearson entre os valores genéticos preditos obtidos.

Para as análises das características de crescimento (PN, PD e GP), os animais foram agrupados em 161 grupos de contemporâneos (GC), compostos por pelo menos três animais nascidos no mesmo mês e ano e pertencentes ao mesmo sexo. Para a idade ao primeiro parto (IPP), os animais foram agrupados em 64 grupos de contemporâneas (GC), sendo cada grupo composto por pelo menos três matrizes nascidas no mesmo mês e ano. Para as características peso total de crias ao nascimento por matriz (PTCN), peso total de crias ao desmame por matriz (PTCD) e período de gestação (PG), foram constituídos 61 grupos contemporâneos, e para o intervalo de partos (IDP) foram considerados 55 grupos contemporâneos, sendo que as matrizes em cada grupo pariram no mesmo mês e ano.

Para as características peso ao nascer, peso ao desmame e ganho de peso, foram considerados os efeitos aleatórios genéticos aditivos, direto e materno, o ambiente permanente materno e os residuais, enquanto que, como efeitos fixos, foram considerados grupo de contemporâneos, interação sexo com tipo de nascimento (um macho, uma fêmea, dois machos, duas fêmeas, um macho e uma fêmea, outros) e classe de idade da mãe ao parto. Também, foram incluídas as covariáveis para a obtenção das estimativas dos efeitos genéticos aditivos diretos de cada raça, do efeito da heterose individual e heterose materna e o efeito de recombinação (modelo 1a, descrito a seguir).

Para as características peso total das crias ao nascer por matriz, peso total das crias ao desmame por matriz, intervalo de parto e período de gestação, incluíram-se o efeito genético aditivo direto e o efeito de ambiente permanente do animal como aleatórios, e os efeitos de grupo de contemporâneas, interação entre sexo e tipo de nascimento das crias e ordem de parto, além das covariáveis para a obtenção das estimativas do efeito genético aditivo direto de cada raça, da heterose individual e de recombinação (modelo 2).

Para a IPP, foi utilizado o modelo 3, semelhante ao modelo 2, excluindo apenas o efeito de ambiente permanente.

Os modelos utilizados podem ser descritos da seguinte forma:

$\mathrm{y}=\mathrm{X} \beta+\mathrm{b}_{1} \mathrm{Dg}_{\mathrm{a}} \mathrm{do}+\mathrm{b}_{2} \mathrm{Dg}_{\mathrm{a}} \mathrm{po}+\mathrm{b}_{3} \mathrm{Dg}_{\mathrm{a}} \mathrm{so}+\mathrm{b}_{4} \mathrm{H}_{\mathrm{i}} \mathrm{dopo}+$ $\mathrm{b}_{5} \mathrm{H}_{\mathrm{i}}$ dosi $+\mathrm{b}_{6} \mathrm{H}_{\mathrm{i}}$ doso $+\mathrm{b}_{7} \mathrm{H}_{\mathrm{i}}$ posi $+\mathrm{b}_{8} \mathrm{H}_{\mathrm{i}}$ poso $+\mathrm{b}_{9} \mathrm{H}_{\mathrm{i}}$ siso + $\mathrm{b}_{10} \mathrm{R}+\mathrm{b}_{11} \mathrm{H}_{\mathrm{m}}$ dopo $+\mathrm{b}_{12} \mathrm{H}_{\mathrm{m}}$ dosi $+\mathrm{b}_{13} \mathrm{H}_{\mathrm{m}}$ doso $+\mathrm{b}_{14} \mathrm{H}_{\mathrm{m}}$ posi
$+\mathrm{b}_{15} \mathrm{H}_{\mathrm{m}}$ poso $+\mathrm{b}_{16} \mathrm{H}_{\mathrm{m}}$ siso $+\mathrm{Za}+\mathrm{Um}+\mathrm{Wp}+\mathrm{e}$

(modelo 1a)

$$
\begin{aligned}
& \mathrm{y}=\mathrm{Xb}+\mathrm{b}_{2} \mathrm{Dg}_{\mathrm{a}} \mathrm{po}+\mathrm{b}_{3} \mathrm{Dg}_{\mathrm{a}} \mathrm{so}+\mathrm{b}_{7} \mathrm{H}_{\mathrm{i}} \text { posi }+\mathrm{b}_{8} \mathrm{H}_{\mathrm{i}} \text { poso }+ \\
& \mathrm{b}_{9} \mathrm{H}_{\mathrm{i}} \text { siso }+\mathrm{b}_{10} \mathrm{R}+\mathrm{Za}+\mathrm{Wc}+\mathrm{e} \\
& \text { (modelo 2) } \\
& \mathrm{y}=\mathrm{Xb}+\mathrm{b}_{2} \mathrm{Dg}_{\mathrm{a}} \mathrm{po}+\mathrm{b}_{3} \mathrm{Dg}_{\mathrm{a}} \mathrm{so}+\mathrm{b}_{7} \mathrm{H}_{\mathrm{i}} \text { posi }+\mathrm{b}_{8} \mathrm{H}_{\mathrm{i}} \text { poso }+ \\
& \mathrm{b}_{9} \mathrm{H}_{\mathrm{i}} \mathrm{siso}+\mathrm{b}_{10} \mathrm{R}+\mathrm{Za}+\mathrm{e}
\end{aligned}
$$

Em que y é o vetor de observações para as características estudadas; b é o vetor dos efeitos fixos; $\mathrm{Dg}_{\mathrm{a}} \mathrm{do}, \mathrm{Dg}_{\mathrm{a}}$ po e $\mathrm{Dg}_{\mathrm{a}}$ so são as proporções esperadas no indivíduo de genes da raça Dorper (do), Poll Dorset (po) e Somalis Brasileira (so), respectivamente; $\mathrm{H}_{\mathrm{i}}$ dopo, $\mathrm{H}_{\mathrm{i}}$ dosi, $\mathrm{H}_{\mathrm{i}}$ doso, $\mathrm{H}_{\mathrm{i}}$ posi, $\mathrm{H}_{\mathrm{i}}$ poso e $\mathrm{H}_{\mathrm{i}}$ siso são as proporções esperadas no indivíduo de locos em heterozigose específica entre as raças indicadas (do = Dorper; po = Poll Dorset; si = Santa Inês; so = Somalis Brasileira); R é a recombinação esperada de pares de locos originados das diferentes raças; $\mathrm{H}_{\mathrm{m}}$ dopo, $\mathrm{H}_{\mathrm{m}}$ dosi, $\mathrm{H}_{\mathrm{m}}$ doso, $\mathrm{H}_{\mathrm{m}}$ posi, $\mathrm{H}_{\mathrm{m}}$ poso e $\mathrm{H}_{\mathrm{m}}$ siso são as proporções esperadas na mãe do indivíduo de locos em heterozigose específica entre as raças indicadas; a é o vetor de efeitos aleatórios genéticos aditivos diretos; $\mathbf{m}$ é o vetor de efeitos aleatórios genéticos aditivos maternos; p é o vetor de efeitos aleatórios de ambiente permanente materno; c é o vetor de efeitos aleatórios de ambiente permanente do animal; e é o vetor de efeitos residuais aleatórios; X, Z, U e W são matrizes de incidência relacionando os registros aos efeitos fixos, genéticos aditivos diretos, genéticos aditivos maternos e de ambiente permanente materno ou do animal, respectivamente; $b_{1} a b_{16}$ são coeficientes de regressão.

É importante destacar que a proporção de genes da raça Santa Inês $\left(G_{a}\right.$ si) não foi incluída nos modelos em função da dependência das proporções das demais raças. Assim, os efeitos genéticos aditivos de cada raça (Dorper, Poll Dorset e Somalis Brasileira) foram estimados como um desvio em relação ao desempenho da raça Santa Inês.

As proporções esperadas no indivíduo de locos em heterozigose específica entre duas raças $\left(\mathrm{H}_{\mathrm{i}} \mathrm{xy}\right)$ foram calculadas como a proporção esperada de genes do pai e da mãe que diferiram a respeito das duas raças em questão. Por exemplo, a proporção esperada no indivíduo de locos em heterozigose com respeitos às raças Dorper e Santa Inês, $\mathrm{H}_{\mathrm{i}}$ dosi, foi calculada como $\left(\operatorname{Dg}_{\mathrm{a}} \mathrm{do}^{\mathrm{p}} \mathrm{x} \mathrm{Dg}_{\mathrm{a}} \mathrm{si}^{\mathrm{m}}\right)+\left(\mathrm{Dg}_{\mathrm{a}} \mathrm{si}^{\mathrm{p}} \mathrm{x}\right.$ $\left.\mathrm{Dg}_{\mathrm{a}} \mathrm{do}^{\mathrm{m}}\right)$, em que $\mathbf{p}$ e $\mathbf{m}$ representam os genes que vieram do pai e da mãe, respectivamente. De forma semelhante, foram calculadas as proporções esperadas na mãe do indivíduo de locos em heterozigose específica entre duas 
raças; mas, nesse caso, os sobrescritos, $\mathbf{p}$ e $\mathbf{m}$, denotam que os genes vieram do avô materno e da avó materna, respectivamente. Utilizando as definições dadas por Dickerson (1973), a recombinação total foi calculada como a soma das recombinações específicas entre duas raças por meio da seguinte expressão: $\mathrm{R}=\left[\left(\mathrm{Dg}_{\mathrm{a}} \mathrm{do}^{\mathrm{p}} \times \mathrm{Dg}_{\mathrm{a}} \mathrm{po}^{\mathrm{p}}\right)+\right.$ $\left(\mathrm{Dg}_{\mathrm{a}} \mathrm{do}^{\mathrm{m}} \times \mathrm{Dg}_{\mathrm{a}} \mathrm{po}^{\mathrm{m}}\right)+\left(\mathrm{Dg}_{\mathrm{a}} \mathrm{do}^{\mathrm{p}} \times \mathrm{Dg}_{\mathrm{a}} \mathrm{si}^{\mathrm{p}}\right)+\left(\mathrm{Dg}_{\mathrm{a}} \mathrm{do}^{\mathrm{m}} \mathrm{x}\right.$ $\left.\mathrm{Dg}_{\mathrm{a}} \mathrm{si}^{\mathrm{m}}\right)+\left(\mathrm{Dg}_{\mathrm{a}} \mathrm{do}^{\mathrm{p}} \times \mathrm{Dg}_{\mathrm{a}} \mathrm{so}^{\mathrm{p}}\right)+\left(\mathrm{Dg}_{\mathrm{a}} \mathrm{do}^{\mathrm{m}} \times \mathrm{Dg}_{\mathrm{a}} \mathrm{so}^{\mathrm{m}}\right)+$ $\left(\mathrm{Dg}_{\mathrm{a}} \mathrm{po}^{\mathrm{p}} \times \mathrm{Dg}_{\mathrm{a}} \mathrm{si}^{\mathrm{p}}\right)+\left(\mathrm{Dg}_{\mathrm{a}} \mathrm{po}^{\mathrm{m}} \times \mathrm{Dg}_{\mathrm{a}} \mathrm{si}^{\mathrm{m}}\right)+\left(\mathrm{Dg}_{\mathrm{a}} \mathrm{po}^{\mathrm{p}} \times \mathrm{Dg}_{\mathrm{a}} \mathrm{so}^{\mathrm{p}}\right)$ $+\left(\mathrm{Dg}_{\mathrm{a}} \mathrm{po}^{\mathrm{m}} \times \mathrm{Dg}_{\mathrm{a}} \mathrm{so}^{\mathrm{m}}\right)+\left(\mathrm{Dg}_{\mathrm{a}} \mathrm{si}^{\mathrm{p}} \mathrm{x} \mathrm{Dg}_{\mathrm{a}} \mathrm{so}^{\mathrm{p}}\right)+\left(\mathrm{Dg}_{\mathrm{a}} \mathrm{si}^{\mathrm{m}} \mathrm{x}\right.$ $\left.\left.\mathrm{Dg}_{\mathrm{a}} \mathrm{So}^{\mathrm{m}}\right)\right]$.

Adicionalmente, com o objetivo de investigar o efeito geral das heteroses individual e materna sobre as características estudadas, foi utilizado um modelo alternativo que, em vez de considerar as heterozigoses individual e materna fracionadas de acordo com as raças envolvidas, incluiu o somatório $\mathrm{H}_{\mathrm{i}}=\mathrm{H}_{\mathrm{i}}$ dopo $+\mathrm{H}_{\mathrm{i}}$ dosi $+\mathrm{H}_{\mathrm{i}}$ doso $+\mathrm{H}_{\mathrm{i}}$ posi $+\mathrm{H}_{\mathrm{i}}$ poso $+\mathrm{H}_{\mathrm{i}}$ siso e $\mathrm{H}_{\mathrm{m}}=\mathrm{H}_{\mathrm{m}}$ dopo $+\mathrm{H}_{\mathrm{m}}$ dosi $+\mathrm{H}_{\mathrm{m}}$ doso + $\mathrm{H}_{\mathrm{m}}$ posi $+\mathrm{H}_{\mathrm{m}}$ poso $+\mathrm{H}_{\mathrm{m}}$ siso para identificar a significância das heteroses individual e materna nas características de crescimento.

O modelo alternativo pode ser representado por (símbolos definidos anteriormente):

$$
\begin{array}{r}
y=X \beta+b_{1} D_{a} \text { do }+b_{2} D_{a} p o+b_{3} D_{a} \text { so }+b_{4} H_{i}+b_{10} R \\
+b_{11} H_{m}+Z a+U m+W p+e \\
(\text { modelo } 1 b)
\end{array}
$$

\section{Resultados e Discussão}

Enquanto a diferença do efeito médio dos genes da raça Dorper ( $\mathrm{Dg}_{\mathrm{a}} \mathrm{do}$ ) não foi significativa em relação ao efeito médio dos genes da raça Santa Inês ( $\left.\mathrm{Dg}_{\mathrm{a}} \mathrm{si}\right)$, as diferenças dos efeitos médios dos genes das raças Poll Dorset ( $\left.\mathrm{Dg}_{\mathrm{a}} \mathrm{po}\right)$ e Somalis Brasileira $\left(\mathrm{Dg}_{\mathrm{a}} \mathrm{so}\right)$ apresentaram desvios significativos de $-0,47 \mathrm{~kg} \mathrm{e}-1,47 \mathrm{~kg}$, respectivamente, sobre o peso ao nascer (Tabela 1, modelo 1a). Esses resultados indicaram que o efeito médio dos genes da raça Santa Inês leva a maiores pesos ao nascer em relação às raças Poll Dorset e Somalis Brasileira.

Nenhum dos efeitos genéticos não-aditivos foi estatisticamente significativo (Tabela 1, modelo 1a). Porém, observou-se efeito significativo e positivo da heterozigose materna sobre o peso ao nascer quando as heterozigoses individual e materna foram consideradas a partir das heterozigosidades totais esperadas (Tabela 1, modelo 1b). Os resultados indicaram que o peso ao nascer foi influenciado principalmente pelos efeitos genéticos aditivos, podendo a heterose materna apresentar algum efeito positivo, enquanto que nenhum efeito de heterose individual ou epistático foi detectado.

Ao contrário dos resultados obtidos, foram encontrados efeitos significativos das heteroses individual e materna sobre o peso ao nascer em ovinos mestiços das

Tabela 1 - Estimativas das diferenças dos efeitos genéticos aditivos, de recombinação e das heteroses para as características de crescimento

\begin{tabular}{|c|c|c|c|c|c|c|}
\hline \multirow[t]{3}{*}{ Parâmetro } & \multicolumn{6}{|c|}{ Estimativa \pm erro-padrão } \\
\hline & \multicolumn{2}{|c|}{ Peso ao nascer (kg) } & \multicolumn{2}{|c|}{ Peso ao desmame (kg) } & \multicolumn{2}{|c|}{ Ganho de peso (kg/dia) } \\
\hline & Modelo 1a & Modelo 1b & Modelo 1a & Modelo 1b & Modelo 1a & Modelo 1b \\
\hline $\operatorname{Dg}_{\mathrm{a}}$ do & $-0,53 \pm 0,41^{\mathrm{ns}}$ & $-0,37 \pm 0,25^{\mathrm{ns}}$ & $-0,97 \pm 1,93^{\mathrm{ns}}$ & $1,00 \pm 0,79^{\mathrm{ns}}$ & $-0,010 \pm 0,033^{\mathrm{ns}}$ & $0,025 \pm 0,012^{*}$ \\
\hline $\mathrm{Dg}_{\mathrm{a}} \mathrm{so}$ & $-1,47 \pm 0,16^{* * *}$ & $-1,58 \pm 0,12^{* * *}$ & $-5,45 \pm 0,53^{* * *}$ & $-5,00 \pm 0,47^{* * *}$ & $-0,056 \pm 0,008^{* * *}$ & $-0,056 \pm 0,007^{* * *}$ \\
\hline $\mathrm{H}_{\mathrm{i}}$ & & $0,07 \pm 0,06^{\mathrm{ns}}$ & & $0,53 \pm 0,25^{*}$ & & $0,004 \pm 0,004^{\mathrm{ns}}$ \\
\hline $\mathrm{H}_{\mathrm{i}}$ doso & $0,15 \pm 0,20^{\mathrm{ns}}$ & & $2,02 \pm 1,01^{*}$ & & $0,025 \pm 0,017^{\mathrm{ns}}$ & \\
\hline $\mathrm{H}_{\mathrm{i}}$ posi & $0,13 \pm 0,08^{\mathrm{ns}}$ & & $0,31 \pm 0,39^{\mathrm{ns}}$ & & $0,001 \pm 0,006^{\mathrm{ns}}$ & \\
\hline $\mathrm{H}_{\mathrm{i}}$ poso & $-0,02 \pm 0,13^{\mathrm{ns}}$ & & $-0,13 \pm 0,48^{\mathrm{ns}}$ & & $-0,015 \pm 0,008^{\mathrm{ns}}$ & \\
\hline $\mathrm{H}_{\mathrm{i}}$ siso & $-0,11 \pm 0,10^{\mathrm{ns}}$ & & $0,91 \pm 0,38^{*}$ & & $0,009 \pm 0,006^{\mathrm{ns}}$ & \\
\hline $\mathrm{R}$ & $0,02 \pm 1,70^{\mathrm{ns}}$ & $-2,46 \pm 1,42^{\mathrm{ns}}$ & $-17,35 \pm 7,57^{*}$ & $-16,55 \pm 6,55^{* *}$ & $-0,323 \pm 0,131^{*}$ & $-0,256 \pm 0,114^{*}$ \\
\hline $\mathrm{H}_{\mathrm{m}}$ & & $0,78 \pm 0,34^{*}$ & & $4,99 \pm 1,63^{* *}$ & & $0,082 \pm 0,028^{* *}$ \\
\hline $\mathrm{H}_{\mathrm{m}}$ poso & $0,35 \pm 0,42^{\mathrm{ns}}$ & & $5,95 \pm 1,91^{* *}$ & & $0,108 \pm 0,033^{* * *}$ & \\
\hline $\mathrm{H}_{\mathrm{m}}$ siso & $0,09 \pm 0,44^{\mathrm{ns}}$ & & $5,61 \pm 1,96^{* *}$ & & $0,105 \pm 0,034^{* *}$ & \\
\hline
\end{tabular}
em ovinos mestiços

*** $\mathrm{P}<0,001 ; * * \mathrm{P}<0,01 ; * \mathrm{P}<0,05 ;{ }^{\text {ns }} \mathrm{P}>0,05$ - ns não-significativo. 
raças Awasi e Chios por Mavrogenis (1996) e em ovinos mestiços da raça Merino (Analla et al., 1998). Bittante et al. (1996) verificaram apenas o efeito significativo da heterose materna em ovinos mestiços das raças Lamon e Finnsheep. Em caprinos mestiços das raças Anglo-nubiana, Galla e Toggenburg, Mugambi et al. (2007) observaram o efeito da heterose individual.

A diferença dos genes das raças Poll Dorset e Somalis Brasileira proporcionaram desvios significativos de $1,02 \mathrm{~kg}$ e -5,46 kg, respectivamente, em relação aos genes da raça Santa Inês (Tabela 1, modelo 1a). Esses resultados evidenciam que, nas condições estudadas, quanto maior a percentagem de genes da raça Poll Dorset no cordeiro, maior tende a ser o peso ao desmame, enquanto que o aumento da participação dos genes da raça Somalis Brasileira levaria a um menor peso ao desmame.

Analisando as estimativas dos efeitos de heterozigose individual específica (Tabela 1, modelo 1a), verificou-se que apenas os efeitos da heterozigose individual entre Dorper e Somalis Brasileira ( $\mathrm{H}_{\mathrm{i}}$ doso) e entre Santa Inês e Somalis Brasileira ( $\left.\mathrm{H}_{\mathrm{i}} \mathrm{siso}\right)$ foram significativos, demonstrando que o cruzamento de reprodutores Dorper ou Santa Inês com matrizes Somalis Brasileira poderiam produzir uma heterose individual positiva para o peso ao desmame. Logo, nesses cruzamentos a heterose individual levaria a um melhor desempenho no peso ao desmame.

O efeito da recombinação (R) foi significativo e negativo, indicando que o acasalamento de animais mestiços entre si (bimestiçagem) pode gerar produtos com menor desempenho quanto ao peso ao desmame se comparados aos produtos da primeira geração após cruzamento. Os efeitos das heterozigoses maternas específicas foram todos significativos e positivos $(\mathrm{P}<0,01)$, exceto para heterozigose materna entre Dorper e Poll Dorset ( $\mathrm{H}_{\mathrm{m}}$ dopo). Assim, nesses cruzamentos, a heterose materna levaria a um melhor desempenho no peso ao desmame.

$\mathrm{Dg}_{\mathrm{a}}$ po, $\mathrm{Dg}_{\mathrm{a}}$ do e $\mathrm{Dg}_{\mathrm{a}}$ so representam a diferença do efeito médio dos genes das raças Poll Dorset, Dorper e Somalis Brasileira, respectivamente, expressa como um desvio da efeito médio dos genes da raça Santa Inês; $\mathrm{H}_{\mathrm{i}}$ é o efeito da heterozigose individual total; $\mathrm{H}_{\mathrm{i}} \mathrm{dopo}, \mathrm{H}_{\mathrm{i}}$ dosi, $\mathrm{H}_{\mathrm{i}}$ doso, $\mathrm{H}_{\mathrm{i}}$ posi, $\mathrm{H}_{\mathrm{i}}$ poso e $\mathrm{H}_{\mathrm{i}}$ siso representam o efeito da heterozigose individual entre as raças indicadas ( $\mathrm{po}=$ Poll Dorset, $\mathrm{do}=$ Dorper, $\mathrm{si}$ = Santa Inês e so = Somalis Brasileira); R representa o efeito médio da recombinação; $\mathrm{H}_{\mathrm{m}}$ é o efeito da heterozigose materna total; $\mathrm{H}_{\mathrm{m}}$ dopo, $\mathrm{H}_{\mathrm{m}}$ dosi, $\mathrm{H}_{\mathrm{m}}$ doso, $\mathrm{H}_{\mathrm{m}}$ posi, $\mathrm{H}_{\mathrm{m}}$ poso e $\mathrm{H}_{\mathrm{m}}$ siso representam o efeito da heterozigose materna entre as raças indicadas. (Modelo 1a) considerando as heteroses específicas entre as raças envolvidas nos cruzamentos ou (Modelo 1b) as heteroses totais.

O peso ao desmame tende a ser tanto menor quanto maior for a proporção de genes da raça Somalis Brasileira e quanto maior for a recombinação gênica proveniente da bimestiçagem (Tabela 1). Por outro lado, crias com maior proporção de genes Poll Dorset, geradas e criadas por uma matriz com elevada heterozigose, tenderiam a apresentar maiores pesos ao desmame.

Resultados semelhantes foram encontrados por Mavrogenis (1996), Davis et al. (1998) e Mugambi et al. (2007) para os efeitos significativos das heteroses individual e materna sobre o peso ao desmame. Analla et al. (1998) somente verificou heterose individual sobre o peso ao desmame, enquanto Bittante et al. (1996) somente observou heterose materna. Arthur et al. (1999) encontraram efeito significativo dos efeitos da heterose direta e da recombinação sobre o peso ao desmame, em ovinos mestiços das raças Awasi e Chios.

Para o ganho de peso no período pré-desmame (GP), as estimativas das diferenças dos efeitos genéticos aditivos (Dg ${ }_{\mathrm{a}} \mathrm{po}, \mathrm{Dg}_{\mathrm{a}}$ do e $\mathrm{Dg}_{\mathrm{a}} \mathrm{so}$ ) apresentaram padrão semelhante ao observado para o peso ao desmame. Todavia, quando as heteroses $\left(\mathrm{H}_{\mathrm{i}}\right.$ e $\left.\mathrm{H}_{\mathrm{m}}\right)$ foram analisadas de forma agregada (Tabela 1 - Modelo 1b), a diferença do efeito médio dos genes da raça Dorper desviou-se significativamente da raça Santa Inês.

Os efeitos da heterozigose individual não foram significativos para o ganho de peso pré-desmama, o que não era esperado, uma vez que efeitos significativos de heterose foram observados no peso à desmama. Por outro lado os efeitos significativos e positivos das heterozigoses maternas evidenciaram a grande importância desse fator para o ganho de peso pré-desmame (Tabela 1 , modelos 1 a e 1b). Assim como no peso ao desmame, a heterose materna levou a um melhor desempenho no ganho de peso do nascimento ao desmame. Isso significa que as fêmeas mestiças influenciaram positivamente o crescimento de suas crias, provavelmente devido à maior produção de leite.

O efeito da recombinação foi negativo e significativo $(\mathrm{P}<0,05)$ para essa característica como também para o peso ao desmame, evidenciando a perda de desempenho nos indivíduos produtos da bimestiçagem. Quando as heterozigoses individual e materna foram consideradas como heterozigosidades totais esperadas (modelo 1b), observou-se um efeito significativo e positivo da diferença do efeito médio dos genes da raça Dorper sobre o ganho de peso do nascimento ao desmame (Tabela 1 - modelo 1a). 
Resultados semelhantes foram encontrados por Davis et al. (1998) para os efeitos significativos das heteroses individual e materna sobre o ganho de peso do nascimento à desmama. Arthur et al. (1999) observaram efeito significativo dos efeitos da heterose direta e da recombinação sobre o ganho de peso do nascimento ao desmame.

A diferença do efeito médio dos genes da raça Somalis Brasileira $\left(\mathrm{Dg}_{\mathrm{a}} \mathrm{so}\right)$ resultou em menores pesos totais das crias ao nascer (PTCN) e ao desmame (PTCD), em relação à diferença do efeito médio dos genes da raça Santa Inês (Tabela 2). Matrizes com maior proporção de genes da raça Somalis Brasileira tenderam a produzir menos quilogramas de cordeiros ao nascimento e ao desmame do que matrizes Santa Inês, enquanto que a diferença genética aditiva da raça Poll Dorset (Dg ${ }_{a}$ po) em relação à raça Santa Inês foi negativa para o peso total das crias ao nascer. Entretanto, uma possível vantagem das matrizes da raça Santa Inês em relação às da raça Poll Dorset não se refletiu sobre o peso total das crias ao desmame (Tabela 2).

Analisando as estimativas dos efeitos de heterozigose individual (Tabela 2), praticamente todos os efeitos foram significativos e positivos, tanto para peso total das crias ao nascer quanto para peso total das crias ao desmame. A única exceção foi a heterozigose entre Santa Inês e Somalis Brasileira $\left(\mathrm{H}_{\mathrm{i}} \mathrm{siso}\right)$, que não foi significativa para peso total das crias ao desmame. Tais resultados indicaram benefícios dos cruzamentos para elevação da produtividade das matrizes em termos de peso total das crias ao nascer e peso total das crias ao desmame, mediante o efeito da heterose individual.

Resultados semelhantes foram encontrados por Bittante et al. (1996) e Davis et al. (1998) para os efeitos das heteroses individual e materna sobre o peso total das crias ao nascer. Boujenane et al. (1999) somente verificaram efeito da heterose individual sobre os pesos totais das crias ao nascer e ao desmame em ovinos mestiços das raças Sadir e D’man. El Fadili \& Leroy (2001) não observaram efeitos significativos das heteroses individuais e maternas sobre o peso total das crias ao nascer, porém esses efeitos foram importantes para o peso total das crias ao desmame, em ovinos mestiços das raças D'man e Timahdite.

O efeito da recombinação (R) não influenciou significativamente as características peso total das crias ao nascer e peso total das crias ao desmame. Todavia, é importante que se observe que as estimativas desse efeito apresentaram elevados erros-padrão, provavelmente em função do pequeno número de registros de desempenho de matrizes bimestiças. Tais resultados estão de acordo com El Fadili \& Leroy (2001), que também não encontraram efeito significativo da recombinação nas características peso total das crias ao nascer e peso total das crias ao desmame.

A idade ao primeiro parto (IPP) foi influenciada significativamente por todos os efeitos incluídos no modelo, exceto pela heterozigose entre as raças Santa Inês e Somalis Brasileira (Tabela 2).

As estimativas indicam que uma maior proporção de genes da raça Somalis Brasileira resultaria em matrizes com menor idade ao primeiro parto, enquanto a diferença do efeito dos genes da raça Poll Dorset levaria ao indesejável aumento da idade ao primeiro parto.

A significância dos efeitos $\mathrm{H}_{\mathrm{i}}$ posi e $\mathrm{H}_{\mathrm{i}}$ poso indicou que o cruzamento com as raças locais (Santa Inês e Somalis Brasileira) é uma alternativa para reduzir a idade ao primeiro parto. A recombinação também teve efeito significativo e negativo, ao contrário do que se verificou para a maioria das características de crescimento, o que é favorável sobre a idade ao primeiro parto.

A não significância da diferença do efeito genético aditivo para o intervalo de partos indicou que as raças Somalis Brasileira e Poll Dorset apresentaram desempenho semelhante à raça Santa Inês para essa característica. Apenas as heterozigoses envolvendo a raça Somalis Brasileira $\left(\mathrm{H}_{\mathrm{i}}\right.$ poso e $\mathrm{H}_{\mathrm{i}}$ siso $)$ influenciaram significativamente

Tabela 2 - Estimativas das diferenças dos efeitos genéticos aditivos, de recombinação e de heterose individual sobre as características de habilidade materna e para as características reprodutivas

\begin{tabular}{|c|c|c|c|c|c|}
\hline \multirow[b]{2}{*}{ Parâmetros } & \multicolumn{5}{|c|}{ Estimativa \pm erro-padrão } \\
\hline & $\begin{array}{c}\text { Peso total das } \\
\text { crias ao nascer }(\mathrm{kg})\end{array}$ & $\begin{array}{l}\text { Peso total das } \\
\text { crias ao desmame (kg) }\end{array}$ & $\begin{array}{c}\text { Idade ao } \\
\text { primeiro parto (dia) }\end{array}$ & $\begin{array}{l}\text { Intervalo de } \\
\text { partos (dia) }\end{array}$ & $\begin{array}{l}\text { Período de } \\
\text { gestação (dia) }\end{array}$ \\
\hline $\operatorname{Dg}_{a}$ so & $-1,41 \pm 0,07^{* * *}$ & $-3,49 \pm 0,50^{* * *}$ & $-42,58 \pm 17,81^{*}$ & $-3,39 \pm 5,70^{\mathrm{ns}}$ & $-2,45 \pm 0,21^{* * *}$ \\
\hline $\mathrm{Dg}_{\mathrm{a}} \mathrm{po}$ & $-0,50 \pm 0,10^{* * *}$ & $1,12 \pm 0,78^{\mathrm{ns}}$ & $250,69 \pm 23,70^{* * *}$ & $7,68 \pm 10,25^{\mathrm{ns}}$ & $-3,80 \pm 0,30^{* * *}$ \\
\hline $\mathrm{H}_{\mathrm{i}}$ poso & $0,66 \pm 0,15^{* * *}$ & $2,38 \pm 1,15^{*}$ & $-104,83 \pm 29,89^{* * *}$ & $-36,13 \pm 16,49^{*}$ & $-0,90 \pm 0,50^{\mathrm{ns}}$ \\
\hline $\mathrm{H}_{\mathrm{i}} \mathrm{posi}$ & $0,41 \pm 0,10^{* * *}$ & $3,11 \pm 0,67^{* * *}$ & $-139,74 \pm 18,92^{* * *}$ & $7,39 \pm 8,22^{\mathrm{ns}}$ & $-1,43 \pm 0,28^{* * *}$ \\
\hline $\mathrm{H}_{\mathrm{i}}$ siso & $0,42 \pm 0,18^{*}$ & $1,85 \pm 1,32^{\mathrm{ns}}$ & $-45,71 \pm 37,57^{\mathrm{ns}}$ & $-38,27 \pm 17,26^{*}$ & $-1,67 \pm 0,54^{* *}$ \\
\hline $\mathrm{R}$ & $0,48 \pm 0,43^{\mathrm{ns}}$ & $-0,54 \pm 3,53^{\mathrm{ns}}$ & $-357,96 \pm 85,50^{* * *}$ & $57,56 \pm 47,01^{\mathrm{ns}}$ & $-2,76 \pm 1,26^{*}$ \\
\hline
\end{tabular}

*** $\mathrm{P}<0,001 ; * * \mathrm{P}<0,01 ; * \mathrm{P}<0,05 ;{ }^{\mathrm{ns}} \mathrm{P}>0,05$ - não-significativo. $\mathrm{Dg}_{\mathrm{a}} \mathrm{po}$, e $\mathrm{Dg}_{\mathrm{a}}$ so representam a diferença do efeito médio dos genes das raças Poll Dorset e Somalis Brasileira, respectivamente, expressa como um desvio do efeito médio dos genes da raça Santa Inês; $\mathrm{H}_{\mathrm{i}}$ posi, $\mathrm{H}_{\mathrm{i}}$ poso e $\mathrm{H}_{\mathrm{i}}$ siso representam o efeito da heterozigose individual entre as raças indicadas (po = Poll Dorset, si = Santa Inês e so = Somalis Brasileira); R representa o efeito médio da recombinação. 
o intervalo de parto (Tabela 2). A partir desses resultados, pode-se afirmar que a utilização de cruzamentos envolvendo a raça Somalis Brasileira contribuiria para menores intervalos de partos.

À exceção da heterozigose entre Poll Dorset e Somalis Brasileira, todos os efeitos estudados influenciaram significativamente para um menor período de gestação (Tabela 2). Assim, pode-se inferir que os genes das raças Somalis Brasileira e Poll Dorset contribuíram para um menor PG, sendo os cruzamentos da raça Santa Inês com essas raças uma forma de reduzir tal característica. Todavia, não seria desejável a alteração nessa característica dada a possibilidade de associações negativas com outras características, como o peso ao nascer e a mortalidade das crias. Além disso, a recombinação, ao contrário do que se verificou para a maioria das características de crescimento, teria um efeito favorável sobre o período de gestação.

A estimativa de herdabilidade direta para o peso ao nascer (Tabela 3) foi moderada, indicando a existência de variabilidade genética passível de ser explorada por meio da seleção. As estimativas de herdabilidade direta para as características peso ao desmame (PD) e ganho de peso do nascimento ao desmame (GP) apresentaram baixa magnitude. Resposta à seleção para o PD e o GP depende fundamentalmente de uma maior acurácia na identificação dos valores genéticos individuais.

As estimativas de herdabilidade materna seguiram a mesma tendência que as de herdabilidade direta. A herdabilidade materna também foi de moderada a alta magnitude para a característica peso ao nascer, indicando grande influência genética da matriz sobre o cordeiro. Enquanto para as características peso ao desmame e ganho de peso do nascimento ao desmame, a contribuição do efeito materno foi menor, indicando pouca influência da variação genética aditiva entre as matrizes sobre os cordeiros.
Esses resultados são coerentes com as estimativas dos efeitos genéticos dos cruzamentos (Tabela 1), que mostram que o peso ao nascer foi basicamente influenciado pelos efeitos genéticos aditivos ( $G_{i}$ do, $G_{i}$ po e $G_{i}$ so), enquanto o peso ao desmame e o ganho de peso do nascimento ao desmame foram fortemente influenciados por efeitos genéticos não-aditivos (heteroses individual e materna e recombinação).

Estimativas de herdabilidades diretas maiores foram obtidas por Silva \& Araújo (2002), Hassen et al. (2003) e Sousa, J. et al. (2006) para características de crescimento. Entretanto, Maria et al. (1993) e Mousa et al. (1999) encontraram herdabilidades diretas menores para peso ao nascer e maiores para peso ao desmame e ganho de peso pré-desmama. Estimativas de herdabilidade materna menor para peso ao nascer e maiores para peso ao desmame e ganho de peso do nascimento ao desmame foram obtidas por Maria et al. (1993), Mousa et al. (1999), Hassen et al. (2003) e Sousa, J. et al. (2006). Logo, pode se constatar que as estimativas de herdabilidade observadas neste estudo estão de acordo com as encontradas na literatura.

O efeito do ambiente permanente da mãe foi importante para todas as características de crescimento, o que justifica sua inclusão nos modelos de análises. Vale destacar que as estimativas de repetibilidade materna $t_{m}$ foram de magnitude moderada a baixa, o que contraindica o descarte de matrizes baseado em apenas uma informação de peso ao nascer e ao desmame de suas crias (Tabela 3).

As estimativas de herdabilidade para as características reprodutivas e de habilidade materna (Tabela 4) foram de moderada a baixa magnitude, sendo moderada para a idade ao primeiro parto e peso total das crias ao nascer e baixas para o período de gestação, peso total das crias ao desmame e intervalo de partos. As estimativas indicam que essas características são altamente influenciadas pelo ambiente.

Tabela 3 - Estimativas de componentes de variância, herdabilidade e covariância entre efeitos diretos e maternos para as características de crescimento em ovinos mestiços

\begin{tabular}{cccc}
\hline Parâmetro & Peso ao nascer & Peso ao desmame & Ganho de peso \\
\hline$\sigma^{2}{ }_{p}$ & $0,4826 \mathrm{~kg}^{2}$ & $6,9185 \mathrm{~kg}^{2}$ & $0,00214(\mathrm{~kg} / \mathrm{dia})^{2}$ \\
$\sigma^{2}{ }^{\mathrm{pm}}$ & $0,0385 \mathrm{~kg}^{2}$ & $0,5119 \mathrm{~kg}^{2}$ & $0,00015(\mathrm{~kg} / \mathrm{dia})^{2}$ \\
$\sigma^{2}{ }^{2}$ & $0,2192 \mathrm{~kg}^{2}$ & $4,8053 \mathrm{~kg}^{2}$ & $0,00162(\mathrm{~kg} / \mathrm{dia})^{2}$ \\
$\sigma^{2}{ }^{a}$ & $0,1854 \mathrm{~kg}^{2}$ & $0,9508 \mathrm{~kg}^{2}$ & $0,00020(\mathrm{~kg} / \mathrm{dia})^{2}$ \\
$\sigma_{\mathrm{m}}^{2}$ & $0,1292 \mathrm{~kg}^{2}$ & $0,6186 \mathrm{~kg}^{2}$ & $0,00008(\mathrm{~kg} / \mathrm{dia})^{2}$ \\
$\sigma_{\mathrm{am}}$ & $-0,0898 \mathrm{~kg}^{2}$ & $0,0319 \mathrm{~kg}^{2}$ & $0,00008(\mathrm{~kg} / \mathrm{dia})^{2}$ \\
$\mathrm{~h}^{2}{ }_{\mathrm{d}}$ & $0,38 \pm 0,12$ & $0,14 \pm 0,06$ & $0,10 \pm 0,05$ \\
$\mathrm{~h}^{2}{ }_{\mathrm{m}}$ & $0,27 \pm 0,06$ & $0,09 \pm 0,05$ & $0,04 \pm 0,04$ \\
$\mathrm{t}_{\mathrm{m}}$ & $0,35 \pm 0,03$ & $0,16 \pm 0,03$ & $0,11 \pm 0,03$ \\
$\mathrm{r}_{\mathrm{am}}$ & $-0,58 \pm 0,12$ & $0,04 \pm 0,45$ & $0,66 \pm 0,98$ \\
\hline
\end{tabular}

$\sigma^{2}=$ variância fenotípica; $\sigma^{2}$ = variância de ambiente permanente materno; $\sigma^{2}$ = variância residual; $\sigma^{2}$ = variância genética aditiva direta; $\sigma^{2}$ m variância genética aditiva materna; $\sigma_{\mathrm{am}}=$ covariância genética direta e materna; $\mathrm{h}_{\mathrm{d}}^{2}=$ herdabilidade direta; $\mathrm{h}_{\mathrm{m}}^{2}=$ herdabilidade materna; $\mathrm{t}_{\mathrm{m}}=$ repetibilidade materna; $\mathrm{r}_{\mathrm{am}}=$ correlação entre os efeitos genéticos aditivos direto e materno. 
Tabela 4 - Estimativas de componentes de variância e parâmetros genéticos para as características de habilidade materna e reprodutivas em ovinos mestiços

\begin{tabular}{|c|c|c|c|c|c|}
\hline Parâmetros & $\begin{array}{l}\text { Peso total das } \\
\text { crias ao nascer }\end{array}$ & $\begin{array}{l}\text { Peso total das } \\
\text { crias ao desmame }\end{array}$ & $\begin{array}{c}\text { Idade ao } \\
\text { primeiro parto }\end{array}$ & $\begin{array}{l}\text { Intervalo de } \\
\text { partos }\end{array}$ & $\begin{array}{l}\text { Período de } \\
\text { gestação }\end{array}$ \\
\hline$\sigma_{p}^{2}$ & $0,78 \mathrm{~kg}^{2}$ & $51,47 \mathrm{~kg}^{2}$ & $14.798,29 \mathrm{dia}^{2}$ & $6.452,73 \mathrm{dia}^{2}$ & $7,30 \mathrm{dia}^{2}$ \\
\hline$\sigma_{p e}^{2}$ & $0,03 \mathrm{~kg}^{2}$ & $1,68 \mathrm{~kg}^{2}$ & - & $0,03 \mathrm{dia}^{2}$ & $0,05 \mathrm{dia}^{2}$ \\
\hline$\sigma_{e}^{2}$ & $0,60 \mathrm{~kg}^{2}$ & $47,23 \mathrm{~kg}^{2}$ & $11.662,15 \mathrm{dia}^{2}$ & $6.326,65 \mathrm{dia}^{2}$ & $6,46 \mathrm{dia}^{2}$ \\
\hline$\sigma_{a}^{2}$ & $0,14 \mathrm{~kg}^{2}$ & $2,55 \mathrm{~kg}^{2}$ & $3.136,14 \mathrm{dia}^{2}$ & $126,04 \mathrm{dia}^{2}$ & $0,77 \mathrm{dia}^{2}$ \\
\hline$h^{2}$ & $0,19 \pm 0,04$ & $0,05 \pm 0,02$ & $0,21 \pm 0,08$ & $0,02 \pm 0,03$ & $0,11 \pm 0,03$ \\
\hline $\mathrm{t}$ & $0,23 \pm 0,03$ & $0,08 \pm 0,03$ & - & $0,02 \pm 0,04$ & $0,11 \pm 0,03$ \\
\hline
\end{tabular}

$\sigma^{2}=$ variância fenotípica; $\sigma_{p e}^{2}=$ variância de ambiente permanente (materno para peso total das crias ao nascer por matriz e peso total das crias ao desmame por matriz individual para intervalo de partos e ganho de peso do nascimento ao desmame); $\sigma^{2}{ }_{\mathrm{e}}=$ variância residual; $\sigma^{2}{ }_{\mathrm{a}}=$ variância genética aditiva direta; $\mathrm{h}^{2}{ }_{\mathrm{d}}=$ herdabilidade direta; $\mathrm{t}$ = repetibilidade (materna para peso total das crias ao nascer por matriz e peso total das crias ao desmame por matriz; individual para intervalo de partos e ganho de peso do nascimento ao desmame).

As estimativas das herdabilidades das características idade ao primeiro parto e peso total das crias ao nascer indicaram a existência de variabilidade genética que poderá propiciar ganhos genéticos por meio da seleção. Para as outras características que apresentaram baixas herdabilidades e que sabidamente são muito influenciadas pelo manejo e outras condições ambientais, a utilização de cruzamentos, mantendo elevado nível de heterozigose, contribuiria para um melhor desempenho de forma mais rápida.

Quesada et al. (2002) relataram estimativas de 0,17 para herdabilidade do intervalo de partos em ovinos. El Fadili \& Leroy (2001) obtiveram estimativas de herdabilidades direta de 0,15 para peso total das crias ao nascer por matriz e 0,08 para peso total das crias ao desmame por matriz.

As estimativas de repetibilidade para as características reprodutivas e de habilidade materna variaram de 0,02 a 0,23 , sendo menor para o intervalo de partos.

As correlações genéticas entre as características de crescimento variaram de 0,01 a 0,88 (Tabela 5), enquanto aquelas entre as características reprodutivas e de habilidade materna variaram de $-0,24$ a 0,99 . Chamam atenção as altas correlações positivas entre peso ao desmame e ganho de peso do nascimento ao desmame e entre peso total das crias ao desmame por matriz e idade ao primeiro parto. No primeiro caso o sentido é favorável, indicando que a seleção para o ganho de peso resultaria em ganho genético para o peso ao desmame e vice-versa. Já no segundo caso, o sentido é desfavorável, indicando que a seleção para menores idades ao primeiro parto levaria também a menores pesos totais das crias ao desmame por matriz, o que seria indesejável.

Correlações genéticas em menores magnitudes foram encontradas por Maria et al. (1993) e Mousa et al. (1999) para as características de crescimento. Já Al-Shorepy et al. (2002), Quesada et al. (2002) e Mugambi et al. (2007) encontraram correlações genéticas em magnitudes maiores para as mesmas características. Estimativas de maior magnitude foram encontradas por El Fadili \& Leroy (2001) para as características de habilidade materna.

Tabela 5 - Correlações genéticas entre as características de crescimento, de habilidades maternas e reprodutivas em ovinos mestiços

\begin{tabular}{|c|c|c|c|c|c|c|}
\hline & $\begin{array}{c}\text { Peso ao } \\
\text { nascer } \\
(\mathrm{kg})\end{array}$ & $\begin{array}{c}\text { Peso ao } \\
\text { desmame } \\
(\mathrm{kg})\end{array}$ & $\begin{array}{l}\text { Peso total das } \\
\text { crias ao nascer } \\
(\mathrm{kg})\end{array}$ & $\begin{array}{c}\text { Peso total das } \\
\text { crias ao desmame } \\
(\mathrm{kg})\end{array}$ & $\begin{array}{c}\text { Idade ao } \\
\text { primeiro parto } \\
\text { (dia) }\end{array}$ & $\begin{array}{l}\text { Intervalo } \\
\text { de partos } \\
\text { (dia) }\end{array}$ \\
\hline Peso ao desmame (kg) & $0,30^{* * *}$ & & & & & \\
\hline \multicolumn{7}{|l|}{ Peso total das crias ao nascer $(\mathrm{kg})$} \\
\hline Peso total das crias ao desmame $(\mathrm{kg})$ & & & $0,29^{* * *}$ & & & \\
\hline Idade ao primeiro parto (dia) & & & $0,29^{* * *}$ & $0,99^{* * *}$ & & \\
\hline
\end{tabular}

\section{Conclusões}

Os genes das raças Poll Dorset e Dorper têm papel importante no desempenho ponderal de produtos de cruzamentos e essas raças podem ser indicadas como raças paternas para cruzamentos terminais. O efeito dos genes da raça Santa Inês no peso ao nascer é favorável e o uso desses animais em cruzamentos pode contribuir para diminuir a mortalidade das crias. Os genes da raça Somalis Brasileira contribuem para melhor desempenho reprodutivo. A 
utilização de matrizes F1 (Santa Inês × Somalis Brasileira) em cruzamento terminal com reprodutores Poll Dorset ou Doper deve melhorar a eficiência produtiva e reprodutiva em ambientes tropicais. A redução no desempenho ponderal por meio das perdas por recombinação torna complexa a formação de populações compostas.

\section{Agradecimentos}

À Gaasa e Alimentos LTDA e à Empresa Brasileira de Pesquisa Agropecuária - Embrapa Caprinos, pela concessão dos dados e parceria neste estudo.

\section{Referências}

AKBAS, Y.; BROTherstone, S.; HILL, W.G. Animal model estimation of non-additive genetic parameters in dairy cattle, and their effects on heritability estimation and breeding value prediction. Journal of Animal Breeding and Genetics, v.110, p.105-113, 1993.

AL-SHOREPY, S.A.; ALHADRANU, G.A.; ABDUL WAHAB, K. Genetic and phenotypic parameters for early growth traits in Emirati goat. Small Ruminant Research, v.45, p.217-223, 2002.

ANALLA, M.; MONTILLA, J.M.; SERRADILLA, J.M. Analyses of lamb weight and ewe litter size in various lines of Spanish Merino sheep. Small Ruminant Research, v.29, p.225-259, 1998.

ARTHUR, P.F.; HEARNSHAW, H.; STEPHENSON, P.D. Direct and maternal additive and heterosis effects from crossing Bos indicus and Bos taurus cattle: cow and calf performance in two environments. Livestock Production Science, v.57, p.231-241, 1999.

BitTANTE, G.; GALlO, L.; CARNIER, P. et al. Effects on fertility and litter traits under accelerated lambing scheme in crossbreeding between Finnsheep and an Alpine sheep breed. Small Ruminant Research, v.23, p.43-50, 1996.

BOCCHI, A.L.; OLIVEIRA, H.N.; FERRAZ, J.B.S. et al. Avaliação genética multirracial para ganho de peso pré-desmama em bovinos de uma população composta. Revista Brasileira de Zootecnia, v.37, n.7, p.1207-1215, 2008.

BOUJENANE, I.; CHAFIK, A.; BENBIHI, M. Heterosis retained in different generations of inter se mating between D'man and Sardi sheep. Journal of Animal Breeding and Genetics, v.116, p.151-159, 1999.

BOLDMAN, K.G.; KRIESE, L.A.; VAN VLECK, L.D. et al. A manual for use of MTDFREML: a set of programs to obtain estimates of variance and covariance. Lincoln: Agricultural Research Service, 1995. 120p. [DRAFT].

COSTA, N.G. A cadeia produtiva de carne ovina no Brasil rumo às novas formas de organização da produção. 2007. 182f. Dissertação (Mestrado em Agronegócios) - Universidade de Brasília/Faculdade de Agronomia e Medicina Veterinária, Brasília.

DAVIS, K.C.; KRESS, D.D.; DOORNBOS, D.E. et al. Heterosis and breed additive effects for Hereford, Tarentaise, and the reciprocal crosses for calf traits. Journal of Animal and Science, v.76, p.701-705, 1998.
DICKERSON, G.E. Inbreeding and heterosis in animals. In: ANIMAL BREEDING AND GENETICS SYMPOSIUM IN HONOR OF DR. JAY L. LUSH, 1973, Champaing. Proceedings... Champaing: American Society of Animal Science, 1973. p.54-77.

EL FADILI, M.; LEROY, P.L. Estimation of additive and nonadditive genetic parameters for reproduction, growth, and survival traits in crosses between the Moroccan D'Man and Timahdite breeds. Journal Animal Breeding and Genetics, v.118, p.341-353, 2001.

EUCLIDES FILHO, K. O melhoramento genético e os seus cruzamentos em bovinos de corte. Campo Grande: EMBRAPA-CNPGC, 1996. 35p. (Documentos, 63).

FALCONER, D.S.; MACKAY, T.F.C. Introduction to quantitative genetics. Hatlow: Lougman Group Limited, 1996. 464p.

FERRAZ, J.B.S.; ELER, J.P. Avaliação genética multirracial de bovinos de corte. In: REUNIÃO ANUAL DA SOCIEDADE BRASILEIRA DE ZOOTECNIA, 42., 2005, Goiânia. Anais... Goiânia: Sociedade Brasileira de Zootecnia, 2005. p.241-244.

HASSEN, Y.; FUERST-WALTL, B.; SÖLKNER, J. Genetic parameter estimates for birth weight, weaning weight and average daily gain in pure and crossbred sheep in thiopia. Journal Animal Breeding Genetic, v.120, p.29-38, 2003.

MARIA, G.A.; BOLDMAN, K.G.; VAN VLECK, L.D. Estimates of variances due to direct and maternal effects for growth traits of Romanov sheep. Journal of Animal Science, v.71, p.845-849, 1993.

MAVROGENIS, A.P. Environmental and genetic factors influencing milk and growth traits of Awassi sheep in Cyprus. Heterosis and maternal effects. Small Ruminant Research, v.20, p.59-65, 1996.

MOUSA, E.; VAN VLECK, L.D.; LEYMASTER, K.A. Genetic parameters for growth traits for a composite terminal sire breed of sheep. Journal of Animal Science, v.77, p.16591665, 1999.

MUGAMBI, J.N.; WAKHUNGU, J.W.; INYANGALA, B.O. Evaluation of the performance of the Kenya goat composites: additive and non-additive genetic parameters. Small Ruminant Research, v.72, p.149-156, 2007.

PEREIRA, J.C.C. Melhoramento genético aplicado à produção animal. 4.ed. Belo Horizonte: FEPMVZ Editora, 2004. 609p.

QUESADA, M.; McMANUS, C.; COUTO, F.A.A. Efeitos genéticos e fenotípicos sobre características de produção e reprodução de ovinos deslanados no distrito Federal. Revista Brasileira de Zootecnia, v.31, n.1, p.342-349, 2002 (supl.).

SILVA, F.L.R.; ARAÚJO, A.M. [2002]. Estimativas de herdabilidade para pesos em cordeiros mestiços Santa Inês, no Estado do Ceará. In: SIMPÓSIO NACIONAL DE MELHORAMENTO ANIMAL, 3., 2002, Belo Horizonte. Anais eletrônicos... Belo Horizonte. Disponível em: <http://www.sbmaonline.org.br/anais/ iii/palestras/iiip.pdf> Acesso em: 18/10/2007.

SOUSA, J.E.R.; OLIVEIRA, S.M.P.; LIMA, F.A.M. et al. Efeitos genéticos e de ambiente para características de crescimento em ovinos Santa Inês no Estado do Ceará. Revista Ciência Agronômica, v.37, n.3, p.364-368, 2006a.

SOUSA, W.H.; CEZAR, M.F.; LÔBO, R.N.B. et al. Estratégias de cruzamentos para produção de caprinos e ovinos de corte: uma experiência da emepa. In: ENCONTRO NACIONAL DE PRODUÇÃO DE CAPRINOS E OVINOS, 1., 2006, Paraíba. Anais... Paraíba: 2006b. (CD-ROM).

STATISTICAL ANALYSIS SYSTEMS - SAS. User's guide: statistics. Cary: 1999. (CD-ROM).

VAN DER WERF, J.H.J.; DE BOER, W. Estimation of genetic parameters in crossbred population of Black and White dairy cattle. Journal of Dairy Science, v.72, p.2615-2623, 1989. 